\title{
9 \\ POTENCIALIDADES DOS REPOSITÓRIOS INSTITUCIONAIS DAS UNIVERSIDADES FEDERAIS BRASILEIRAS: APONTAMENTOS SOBRE SOFTWARE, EQUIPE, MANUAL, TUTORIAL E POLÍTICA
}

\author{
Leandro da Conceição Borges \\ Mestre em Ciência da Informação pelo Instituto Brasileiro de Informação \\ em Ciência e Tecnologia em Convênio com a Universidade Federal do Rio de \\ Janeiro, Brasil. Bibliotecário da Universidade Federal de Minas Gerais, Brasil. \\ E-mail: leandrocb@bol.com.br

\section{Andressa Gonçalves Castro} \\ Bacharela em Biblioteconomia pela Universidade Federal do Rio de \\ Janeiro, Brasil. Auxiliar em Administração de Biblioteca da Universidade \\ Federal do Rio de Janeiro, Brasil. \\ E-mail: andressagoncalves@iq.ufri.br \\ Diego Martins Aragão da Silva \\ Mestrando em Biblioteconomia pela Universidade Federal do Rio de \\ Janeiro, Brasil. Bibliotecário da Secretaria de Estado de Assistência Social e \\ Direitos Humanos do Rio de Janeiro, Brasil. \\ E-mail: diegoaragao64@yahoo.com.br

\section{Bruna Beltrão Belinato de Vasconcellos} \\ Mestra em Biblioteconomia pela Universidade Federal do Estado do Rio \\ de Janeiro, Brasil. \\ E-mail: bruna.belinato@icict.fiocruz.br

\section{Barbara Christian Vitiello} \\ Bacharela em Biblioteconomia pela Universidade Federal do Rio de \\ Janeiro, Brasil. Auxiliar de Biblioteca do Instituto Federal de Educação, \\ Ciência e Tecnologia do Rio de Janeiro, Brasil. \\ E-mail: babavitiello@gmail.com
}

\section{Resumo}

As universidades federais brasileiras sofreram mudanças substanciais na última década com o projeto de expansão do ensino implantado pelo Governo Federal à época. Com um público crescente, essas mudanças impactaram a demanda por produtos e serviços de informação dessas instituições. Assim, esta pesquisa analisa os apontamentos de software, equipe, manual, tutorial e política das 63 universidades federais presentes no país. Realizado entre os anos de 2017 a 2019, este estudo mapeia essas características nos 49 repositórios institucionais de universidades federais em funcionamento durante as buscas. A pesquisa de caráter descritivo e abordagem quali-quantitativa apresenta ainda os repositórios numericamente, evidenciando as suas diferenças e similaridades, cujos dados foram registrados e transcritos. Os resultados apontaram que, geograficamente, as regiões Sul e Centro-oeste são as únicas em que todas as universidades federais possuem repositórios institucionais, sendo a política o elemento de maior adesão e o manual o quesito de menor engajamento. Logo, conclui-se que alguns desses critérios são adotados de forma incipiente pelos repositórios, sendo os mesmos encontrados em outros sites de setores ou departamentos das instituições e não nos próprios

Perspectivas em Gestão \& Conhecimento, João Pessoa, v. 9, n. 2, p. 245-265, maio/ago. 2019. DOI: http://dx.doi.org/10.21714/2236-417X2019v9n2p245 
repositórios. A adesão dessas questões pelas instituições apresentaria assim maior amplitude da democratização do acesso à informação científica, atingindo todos os atores que buscarem informação em seus repositórios institucionais.

Palavras-chave: Acesso aberto. Universidades federais. Repositório institucional. Brasil.

\title{
POTENTIALITIES OF THE INSTITUTIONAL REPOSITORIES OF BRAZILIAN FEDERAL UNIVERSITIES: NOTES ON SOFTWARE, TEAM, MANUAL, TUTORIAL AND POLICY
}

\begin{abstract}
Brazilian federal universities have undergone substantial changes in the last decade caused by the project of expansion of education implemented by the Federal Government at the time. With a growing public, these changes impacted the demand for information products and services from these institutions. Thus, this research analyzes the software, team, manual, tutorial and policy notes of the 63 federal universities present in the country. Conducted between the years 2017 to 2019, this study maps these characteristics in the 49 institutional repositories of federal universities in operation during the search. The descriptive research and quali-quantitative approach also presents the repositories numerically, evidencing their differences and similarities, whose data were recorded and transcribed. The results showed that, geographically, the South and Midwest regions are the only ones in which all federal universities have institutional repositories, the policy being the element of greater adherence and the manual the item of less engagement. Therefore, it is concluded that some of these criteria are adopted in an incipient way by the repositories, being the same found in other sectors or departments' websites of the institutions and not in the repositories themselves. The adherence of these questions by the institutions would thus present greater amplitude of the democratization of access to scientific information, reaching all the actors who seek information in their institutional repositories.
\end{abstract}

Keywords: Open access. Federal universities. Institutional repository. Brazil.

\section{INTRODUÇÃO}

Os debates suscitados na comunidade científica sobre iniciativas de acesso à informação científica cresceram nas últimas décadas. Os problemas relacionados às limitações impostas por esta iniciativa no século XX contribuíram fortemente para o surgimento do Movimento de Acesso Aberto à informação científica. Este Movimento, que surgiu em um momento que as Tecnologias de Informação e Comunicação (TIC) passam a ser utilizadas como estratégia de difusão da ciência, alcançando um número crescente de pessoas ao conhecimento (BELENS; PORTO, 2009), está estritamente ligado ao desenvolvimento de repositórios digitais, periódicos científicos de acesso aberto, além das discussões atuais sobre dados abertos e a Ciência aberta.

Frente a essas questões que imbuem a ciência moderna, este artigo apresenta a seguinte pergunta de pesquisa: como está delineado o panorama dos repositórios institucionais das universidades federais brasileiras, no que diz respeito à adoção de software, equipe, confecção e elaboração de manuais e/ou tutoriais e políticas? A escolha por esses critérios levou em consideração a pesquisa realizada por Silva (2017) que atenta sobre a importância global desses elementos para o bom funcionamento de um repositório digital. Corroborando ao que Silva (2017) afirmou, Romani, Fusco e Santos (2010) apontam que a composição central de um repositório institucional inclui software, pessoal e conteúdo disponibilizado no mesmo.

A justificativa por estudar repositórios institucionais está no fato dos mesmos apresentarem mecanismos de preservação da memória e gestão da informação de uma

Perspectivas em Gestão \& Conhecimento, João Pessoa, v. 9, n. 2, p. 245-265, maio/ago. 2019. 
instituição, sendo essas, portanto, ferramentas essenciais de difusão do acesso aberto no mundo (PIMENTA et. al, 2016). Mediante a este contexto, em buscas realizadas no mês de julho de 2019, verificou-se no site do Directory of Open Access Repositories (OpenDoar) que a maioria dos repositórios cadastrados no diretório está classificado como institucionais. 0 OpenDoar é um diretório oficial de repositórios de acesso aberto, mantido pela Universidade de Nottingham, Reino Unido, em conjunto com a Universidade de Lund, Suécia, constituindo um grupo de serviços desenvolvidos pela SHERPA (MELIS, 2013). Os dados presentes no OpenDoar, em julho de 2019, reportaram aos seguintes números: 3.650 repositórios estão cadastrados como institucionais; 342 como temáticos ou disciplinares; 128 como agregadores e 104 como governamentais, lembrando que o OpenDoar apresenta um recorte mundial de repositórios digitais.

Os repositórios institucionais também servem de fonte informacional na prestação de contas à sociedade de estudos e pesquisas desenvolvidas pelas instituições públicas, já que, em sua grande maioria, são provenientes de financiamento público (SOBRAL; SANTOS, 2017). Frente a esses resultados, constatou-se que os repositórios institucionais apresentam grande representatividade mundial, o que justifica estudos científicos que contemplam o seu escopo.

A escolha por universidades federais se deu pela importância que as mesmas apresentam no cenário científico e tecnológico nacional, uma vez que grande parte da produção científica brasileira é desenvolvida em universidades, em especial nas universidades públicas (SIDONE; HADDAD; MENA-CHALCO, 2016). Corroborando a esta afirmativa, em ranking divulgado anualmente pelo jornal "Folha de São Paulo", no ano de 2018, o desempenho das universidades brasileiras foi listado em diferentes quesitos. Com esforços centralizados em um Top 10 do ranking, nos quesitos "Ensino", houve a representatividade de oito universidades federais e duas universidades estaduais; em "Melhores Universidades" e "Pesquisa", sete universidades federais e três estaduais, em cada quesito; "Inovação", cinco universidades federais, duas estaduais e três privadas; "Internacionalização", o quadro foi representado por sete universidades federais, duas estaduais e uma privada; e em "Mercado", houve a concentração de três universidades federais, três estaduais e quatro privadas. Atualmente o Brasil possui 63 universidades federais, segundo dados disponibilizados no site do Ministério da Educação (MEC). Cabe lembrar que desde 2017 o Instituto Nacional de Estudos e Pesquisas Educacionais Anísio Teixeira (INEP) inclui repositórios institucionais como um instrumento de avaliação de cursos de graduação e pós-graduação de instituições de ensino superior (MARTINS, 2019). Esta pesquisa foi realizada entre os anos de 2017 a 2019.

O estudo está dividido da seguinte maneira: "Movimento de acesso aberto à informação científica" que apresenta, de forma geral, como se deu o início do Movimento com a "crise dos periódicos" e, como isso, é importante hoje para a Ciência aberta e a questão dos dados abertos de pesquisa. "Metodologia" aborda o percurso metodológico da pesquisa. "Análise dos dados" analisa os quesitos software, equipe, manual, tutorial e política dos repositórios; e as mensagens eletrônicas enviadas, por e-mail ou ouvidorias, aos setores de informação das universidades federais que não possuíam repositórios ou caso os mesmos estivessem fora do ar durante a pesquisa. As "Considerações finais" mostram a direção e tendências que este estudo aponta e, por fim, as "Referências" utilizadas na pesquisa.

\section{MOVIMENTO DE ACESSO ABERTO À INFORMAÇÃO CIENTÍFICA}

Mueller (2006) diz que a estabilidade vivenciada pelo sistema de comunicação científica mundial foi abalada com a chamada "crise dos periódicos", em meados da década de 1980. Segundo a autora, o principal fator que contribuiu para o avanço da crise foi a dificuldade das bibliotecas universitárias e de pesquisas norte-americanas manterem atualizadas as suas coleções de periódicos, uma vez que a cobrança, cada vez mais altas pelas

Perspectivas em Gestão \& Conhecimento, João Pessoa, v. 9, n. 2, p. 245-265, maio/ago. 2019. 
editoras científicas comerciais, tornaram insustentáveis a manutenção da crescente demanda dos usuários por conteúdo atualizado, proveniente de artigos de periódicos comercializados por essas editoras. Na visão de Rodrigues (2004), a crise ocorre no final da década de 1990 e uma das questões estava na dificuldade do acesso à literatura científica, provocada pelas editoras científicas comerciais que cobravam preços crescentes para o acesso aos seus títulos. Divergências temporais à parte, no que diz respeito ao início da crise dos periódicos, tanto Mueller (2006) quanto Rodrigues (2004) concordam que a crise dos periódicos foi essencial para o surgimento do Movimento de acesso aberto à informação científica.

Uma das primeiras iniciativas do Movimento foi a criação, por Paul Ginsparg, do repositório digital temático Arxiv, em 1991, voltado para as áreas de Física, Matemática e ciências não lineares. O objetivo deste repositório estava em disponibilizar, via internet, artigos e outros tipos de documentos acadêmicos, que não haviam passado pela aprovação da revisão pelos pares. Esses documentos são chamados de preprints (CIVALLERO, 2006). Este fato, a não verificação pelos pares, criou, à primeira vista, descrenças da comunidade científica ao Movimento que começava a se desenhar (GUANAES; GUIMARÃES, 2012; SANTOS JÚNIOR, 2010). Frente a essas desconfianças, convenções foram se formando e pontos, até então questionados, começaram a entrar em pauta e ser contemplados.

Em 1999, acontece a Convenção de Santa Fé, no Novo México, Estados Unidos, onde são fixados alguns elementos norteadores ao Movimento como: o autoarquivamento, a revisão pelos pares e a interoperabilidade entre os sistemas que adotavam a filosofia aberta (TRISKA; CAFÉ, 2001). Outras iniciativas, dentro do Movimento de Acesso Aberto, começaram a surgir, dentre elas, o chamado "3Bs" de acesso aberto, denominação dada por Peter Suber (FURNIVAL; HUBBARD, 2011), que constituem as declarações de Budapeste (2002), Bedestha (2003) e Berlim (2003). Dessas, a declaração de Budapeste foi a que definiu o que é acesso aberto, além das duas principais estratégias do Movimento: as vias verde e dourada. Segundo o documento, o acesso aberto consiste na disponibilidade do material na internet, onde o usuário pode "[...] ler, baixar, copiar, distribuir, imprimir, buscar ou usar desta literatura com qualquer propósito legal, sem nenhuma barreira financeira, legal ou técnica que não o simples acesso à internet" (BUDAPEST..., 2002). Cabe lembrar que este propósito não anula a citação à obra de origem em caso de utilização ou transformação da mesma em obras derivadas. Já sobre as duas estratégias de acesso aberto, a via verde é voltada para a disseminação de repositórios digitais (autoarquivamento) e a via dourada para a disseminação de periódicos científicos de filosofia aberta.

Na visão de Hanard et al. (2004), Suber (2004) e Rodrigues (2004), a via verde é tida como a principal na propagação do acesso aberto. Kuramoto (2011) defende que a via verde é a estratégia de acesso aberto que tem por oferecer o melhor custo/benefício por ser a estratégia que mais rapidamente poderá conduzir ao Open Access universal, pois "[...] ela depende única e exclusivamente da comunidade científica ou mais especificamente dos pesquisadores, porque são eles os autores".

Com esforços centrados na via verde, a mesma pode ser subdividida em repositório institucional, repositório temático ou disciplinar, repositório agregador e repositório governamental. Em linhas gerais, os repositórios institucionais são aqueles que armazenam, preservam, gerem e disponibilizam a memória institucional (produção científica de uma instituição) por meio de repositórios centrais que são provedores de serviços nacionais e internacionais (MÁRDERO ARELLANO, 2008). Os repositórios temáticos ou disciplinares são aqueles que armazenam a produção científica baseada em um assunto, área do conhecimento ou temática específica (GUIMARÃES; SILVA; NORONHA, 2012; KURAMOTO, 2006; MONTEIRO; BRÄCHER, 2007). Os repositórios agregadores dispõem de registros (metadados) de outros repositórios (KURAMOTO, 2012), e também de documentos depositados em outros sistemas, constituindo fontes secundárias (SOBRAL; SANTOS, 2017). Os repositórios governamentais

Perspectivas em Gestão \& Conhecimento, João Pessoa, v. 9, n. 2, p. 245-265, maio/ago. 2019. 
reúnem documentos governamentais (KURAMOTO, 2012) que visam a preservação, distribuição, disseminação de documentos e registros legais (SOBRAL; SANTOS, 2017).

Contribuindo para a discussão sobre repositórios e constituindo uma nova tendência de tipologias, Kornalewski, Borges e Belinato (2017) abrem as discussões para o chamado "repositório biográfico". Segundo os autores, esses repositórios constituem em um local no ciberespaço para a guarda documental em alinhamento com a Biblioteconomia, Arquivologia e a Museologia, por meio dos conceitos: instituição, memória, documento e informação, que juntos evidenciam a produção pessoal, científica e acadêmica de um sujeito notório.

Ao contextualizar essas tendências dentro do Movimento de Acesso Aberto, é relevante mencionar as constantes confusões na literatura para os conceitos de acesso aberto e Ciência aberta. Um projeto financiado pela Comissão Europeia para o alcance da Ciência aberta de nome Facilitate Open Science Training for European Research, conhecido como Foster, define a Ciência aberta como uma prática inserida na ciência, em que é possível colaborar e contribuir com o avanço científico através dos dados de pesquisa, notas de laboratório e outras modalidades de pesquisa que estão disponíveis livremente, trazendo a possibilidade de reutilização, redistribuição e reprodutibilidade da pesquisa, assim como, à utilização desses dados em novos métodos (FOSTER, 2018). Na visão de Pinheiro (2014), a Ciência aberta representa uma ampliação do acesso aberto, cuja disponibilização dos dados de pesquisa apresenta a tentativa de tornar o conhecimento científico mais democrático e transparente. Segundo Andrade (2014), a disponibilização dos dados de pesquisa de forma livre é a ponte que faz a progressão do acesso aberto para a Ciência aberta. Outras tendências atuais intrínsecas ao Movimento, que buscam ir de encontro com as práticas da Ciência aberta, estão na criação de repositórios de preprints pela Scientific Electronic Library Online (SciELO) e na alteração do nome da principal conferência em língua portuguesa sobre acesso aberto, que até 2018 era conhecida como "Conferência Luso-brasileira sobre Acesso Aberto" e atualmente passou-se a se chamar "Conferência Luso-brasileira de Ciência Aberta", a CONFOA .

Frente a este cenário delineado acima, pode-se afirmar que os repositórios institucionais se tornaram importantes ferramentas para a disseminação da ciência no mundo. Considerando que um dos papéis da universidade está na produção de conhecimento técnicocientífico e de disseminação da informação, é possível afirmar que os repositórios institucionais constituem um papel estratégico neste processo. A seguir é apresentada a metodologia adotada neste trabalho.

\section{METODOLOGIA}

A pesquisa de cunho descritivo buscou evidenciar características qualitativa e quantitativa dos repositórios. A classificação descritiva é definida por Gil (2007) como uma estratégia que descreve as características da população estudada, neste caso, os repositórios institucionais das universidades federais brasileiras. Sobre as características quantitativa e qualitativa adotadas no estudo, esta contempla o levantamento numérico dos resultados, a partir dos dados organizados para que assim sobressaiam os aspectos qualitativos dos dados coletados. A pesquisa foi realizada entre os anos de 2017 a 2019 e, durante este tempo, foi possível analisar mudanças e peculiaridades nos repositórios.

O primeiro passo foi o mapeamento das universidades federais brasileiras. Tendo o site do MEC como base, cujos resultados estão descritos no quadro 1 , separados por regiões geográficas do Brasil.

Perspectivas em Gestão \& Conhecimento, João Pessoa, v. 9, n. 2, p. 245-265, maio/ago. 2019. 
Quadro 1 - Quantidade de universidades federais no Brasil por região

\begin{tabular}{|l|r|}
\hline Região & Quantidade de universidades federais \\
\hline Sudeste & 19 \\
\hline Nordeste & 18 \\
\hline Sul & 11 \\
\hline Norte & 10 \\
\hline Centro-oeste & 5 \\
\hline Total & $\mathbf{6 3}$ \\
\hline
\end{tabular}

Fonte: Os autores (2019)

Desmembrando a universidade e a sua importância, dados publicados no mês de janeiro de 2018 em um relatório da Clarivate Analytics, informou que Brasil está em décimo terceiro lugar em atividade científica no mundo. E grande parte desses resultados de pesquisa está em acesso aberto. Acredita-se que o material produzido pelos atores que compõem a universidade (docentes, discentes e técnico-administrativos) ao estar em repositórios institucionais constitui uma estratégia de preservação da memória institucional em diferentes suportes, apresentando-se como mecanismo de disseminação de informação e de visibilidade da instituição através da sua produção científica e/ou acadêmica, assim como, abrange elementos de transparência governamental de gastos públicos.

O segundo passo da pesquisa foi a tabulação dos dados no software Microsoft Excel referentes aos critérios software, equipe, manual, tutorial e política. A verificação do software foi possível assim que se acessava o repositório. Para a equipe, quando a informação não estava aparente, verificou-se todas as abas presentes no repositório. Para o manual, tutorial e política, quando não aparentes no repositório, realizou-se estratégias de buscas no campo "pesquisar" dos mesmos com os termos: "tutorial", "manual" e "política". Caso as buscas não trouxessem resultados satisfatórios, realizou-se buscas no Google com a estratégia: "sigla da instituição" + a palavra "manual"; "sigla da instituição" + a palavra "política"; "sigla da instituição" + a palavra "tutorial".

Após a verificação dessas etapas, as informações foram preenchidas no arquivo em Excel. Por fim, a última etapa consistiu em enviar ao setor de informação das universidades, como o sistema de bibliotecas ou similar, mensagens, em dois cenários, com as seguintes questões: 1) para instituições sem repositórios; 2 ) instituições com repositórios inacessíveis durante as buscas. Os quadros 2 e 3 sistematizam essas perguntas.

Cenário 1 - Instituição sem repositório:

Quadro 2 - Perguntas instituição sem repositório

\begin{tabular}{|l|l|}
\hline $\mathbf{1}$ & Existe a possibilidade de a instituição ter algum repositório? \\
\hline $\mathbf{2}$ & Caso sim, quando estaria disponível? \\
\hline $\mathbf{3}$ & Em caso de equívocos, colocar aqui o link do repositório institucional. \\
\hline
\end{tabular}
Fonte: Os autores (2019)

Cenário 2 - Instituição com repositório, mas indisponível no momento da pesquisa:

Quadro 3 - Instituição com repositório, mas indisponível durante a busca

\begin{tabular}{|l|l|}
\hline $\mathbf{1}$ & Qual software vocês utilizam? \\
\hline $\mathbf{2}$ & Existem manuais e tutoriais visíveis no repositório? \\
\hline $\mathbf{3}$ & $\begin{array}{l}\text { Há um detalhamento no repositório da equipe que trabalha para a manutenção do mesmo? Em } \\
\text { caso positivo, este quadro é formado por quantas pessoas? Quais são as suas formações? }\end{array}$ \\
\hline $\mathbf{4}$ & Há política do repositório? Esta política está inserida no repositório ou em alguma outra página? \\
\hline
\end{tabular}

Perspectivas em Gestão \& Conhecimento, João Pessoa, v. 9, n. 2, p. 245-265, maio/ago. 2019. 
$\mathbf{5} \quad$ Há previsão de resolver os problemas de acesso ao repositório?

Fonte: Os autores (2019)

Pensou-se nessas perguntas levando em consideração o respaldo da abrangência da Lei de Acesso à Informação vigente no Brasil, a Lei 12.527/2011, e utilizou-se, em um segundo momento, dos recursos das ouvidorias para as instituições que não responderam as primeiras mensagens enviadas ao setor de informação por e-mail. No quadro 4, é apresentado o panorama dos repositórios institucionais das universidades federais brasileiras em relação à adoção das características pesquisadas: software, equipe, manual, tutorial e política. As características assinaladas com $(\mathrm{X})$ no quadro mostram as entradas que foram encontradas.

Quadro 4 - Universidades federais e a adoção das características: software, equipe, manual, tutorial e política

\begin{tabular}{|c|c|c|c|c|c|}
\hline Instituição & Software & Equipe & Manual & Tutorial & Política \\
\hline UnB & Dspace & $x$ & & & $x$ \\
\hline UFG & Dspace & & & & $x$ \\
\hline UFGD & Dspace & & & & $x$ \\
\hline UFMT & Dspace & & & & \\
\hline UFMS & Dspace & & & & $x$ \\
\hline UFCSPA & Dspace & & & & $x$ \\
\hline UFFS & Dspace & & & & $x$ \\
\hline UFSC & Dspace & & & $x$ & $x$ \\
\hline UNIPAMPA & Dspace & & & $x$ & $x$ \\
\hline FURG & Dspace & $x$ & & $x$ & $x$ \\
\hline UTFPR & Dspace & $x$ & & $x$ & $x$ \\
\hline UNILA & Dspace & & & $x$ & $x$ \\
\hline UFPEI & Dspace & & & & $x$ \\
\hline UFSM & Dspace & & & & \\
\hline UFPR & Dspace & & & $x$ & \\
\hline UFRGS & Dspace & & & $x$ & $x$ \\
\hline UFBA & Dspace & $x$ & $x$ & $x$ & $x$ \\
\hline UFERSA & Dspace & $x$ & & & \\
\hline UFRB & Dspace & & & & $x$ \\
\hline UNILAB & Dspace & & & & \\
\hline UFPB & Dspace & & & & \\
\hline UFAL & Dspace & & & $x$ & $x$ \\
\hline UFPE & Dspace & $x$ & & $x$ & $x$ \\
\hline UFRPE & Dspace & & & & \\
\hline UFS & Dspace & & $x$ & & $x$ \\
\hline UFC & Dspace & & & $x$ & $x$ \\
\hline UFMA & Dspace & & & & \\
\hline UFPI & Dspace & & & & $x$ \\
\hline UFRN & Dspace & $x$ & & $x$ & $x$ \\
\hline UNIR & Dspace & & & & $x$ \\
\hline UFAC & ------------- & |------------ & ----------------- & ----------------- & ---------------- \\
\hline UFAM & Dspace & & & $x$ & $x$ \\
\hline UFPA & Dspace & & & $x$ & \\
\hline UFT & Dspace & & $x$ & & $x$ \\
\hline UFRA & Dspace & & & & $x$ \\
\hline UFRR & Dspace & & & & \\
\hline
\end{tabular}

Perspectivas em Gestão \& Conhecimento, João Pessoa, v. 9, n. 2, p. 245-265, maio/ago. 2019. 


\begin{tabular}{|l|l|l|l|l|l|}
\hline UNIFESSPA & Dspace & & & & \\
\hline UNIFEI & Dspace & & & & $\mathrm{X}$ \\
\hline UFJF & Dspace & & & & \\
\hline UFLA & Dspace & & $\mathrm{X}$ & & $\mathrm{X}$ \\
\hline UFOP & Dspace & $\mathrm{X}$ & & $\mathrm{X}$ & $\mathrm{X}$ \\
\hline UFSCar & Dspace & & $\mathrm{X}$ & $\mathrm{X}$ & $\mathrm{X}$ \\
\hline UNIFESP & Dspace & & $\mathrm{X}$ & & \\
\hline UNIRIO & Dspace & & & & $\mathrm{X}$ \\
\hline UFU & Dspace & $\mathrm{X}$ & & $\mathrm{X}$ & $\mathrm{X}$ \\
\hline UFV & Dspace & & & & $\mathrm{X}$ \\
\hline UFES & Dspace & & & & \\
\hline UFRJ & Dspace & & $\mathrm{X}$ & & $\mathrm{X}$ \\
\hline UFVJM & Dspace & & $\mathrm{X}$ & & $\mathrm{X}$ \\
\hline UFF & Dspace & & & $\mathrm{X}$ & $\mathrm{X}$ \\
\hline
\end{tabular}

Fonte: Os autores (2019)

Esses apontamentos podem ser explicados da seguinte maneira:

a) Software: elemento que proporciona a criação e configuração do repositório;

b) Equipe: recursos humanos que trabalham no repositório;

c) Manual: documento que possibilita as instruções de $\mathrm{A}$ a $Z$ do repositório;

d) Tutorial: documento genérico ao manual que exemplifica, de forma rápida e pontual, uma funcionalidade específica do repositório. O tutorial pode ser elaborado em diferentes suportes, como textos, vídeos, áudios etc.

e) Política: documento que explicita o propósito de existência do repositório.

A seguir, foram analisados os resultados encontrados na pesquisa, e explorados cada critério assinalado na etapa metodológica.

\section{ANÁLISE DOS DADOS}

Das 50 universidades com repositórios, uma estava com acesso indisponível durante a pesquisa: a Universidade Federal do Acre (UFAC). Neste caso, enviou-se e-mail ao setor de informação da instituição e posteriormente, mensagem por meio da ouvidoria da universidade. No tópico 4.6 "Mensagens eletrônicas e ouvidoria", serão apresentadas as respostas para esta e outras universidades conforme as perguntas apresentadas nos dois cenários na etapa metodológica deste trabalho. Portanto, o universo desta pesquisa compõe 49 repositórios institucionais de universidades federais. Abaixo apontamentos de software, equipe, manual, tutorial, política e mensagens eletrônicas enviadas aos setores de informação das universidades.

\subsection{Software}

Dos 49 repositórios com acesso disponível, todos utilizam a plataforma Dspace. Inferese que esta adoção ocorreu devido a orientação da Coordenação de Aperfeiçoamento de Pessoal de Nível Superior (CAPES) que instituiu na Portaria 013/2006 que as instituições deveriam divulgar online a produção das teses e dissertações dos programas de pós-graduação reconhecidos. Somados a isso, o Instituto Brasileiro de Informação em Ciência e Tecnologia (IBICT) publicou, em 2009, o edital FINEP/PCAL/XBDB no 002/2009, que visava apoiar projetos de implantação de repositórios institucionais nas instituições públicas (federais, estaduais e municipais) de ensino e pesquisa, assim como a integração dos mesmos ao Portal oasisbr, com

Perspectivas em Gestão \& Conhecimento, João Pessoa, v. 9, n. 2, p. 245-265, maio/ago. 2019. 
o objetivo de possibilitar a disseminação, visibilidade e ampliação da produção científica dessas instituições.

O IBICT adotou o software Dspace para essas ações e realizou a customização do mesmo, conforme a informação disponível em seu site. O software Dspace é uma iniciativa do Massachusetts Institute of Technology (MIT) e a Hewlett-Packard (HP) e, segundo os seus desenvolvedores, o programa caracteriza-se como: um software sem fins lucrativos ou comerciais para a criação de repositórios digitais livre, com características personalizáveis para atender às necessidades de qualquer organização. Cabe lembrar que o Dspace e o E-prints são os dois principais softwares de repositórios digitais de maior utilização no mundo atualmente (FICHE; MOURA; MAIA, 2017). O Dspace possui uma lista de discussão na internet de usuários do sistema. Na lista, é possível apresentar dúvidas, discussões pontuais, ver notícias, atualizações etc. sobre o sistema.

Sobre a escolha do software a ser adotado para a construção de um repositório, Sobral e Santos (2017) atentam que as instituições tendem a dar importância para o conhecimento das características de navegabilidade do mesmo e optar por modelos já existentes. Esta escolha pode ajudar a auxiliar a instituição em momentos de dúvidas ou dificuldades operacionais futuras com o programa.

A personalização da plataforma Dspace ficou presente quando observou-se o repositório da Universidade de Brasília (UnB) e a Universidade Federal de Pernambuco (UFPE), cuja arquitetura informacional é um pouco diferenciada dos demais repositórios analisados. A figura 1 e a Figura 2 apresentam as divisões das comunidades do repositório da UnB e da UFPE, respectivamente.

Figura 1 - Comunidades repositório institucional UnB

\section{จ Comunidades do repositório}
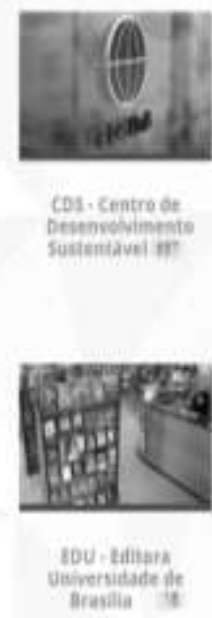
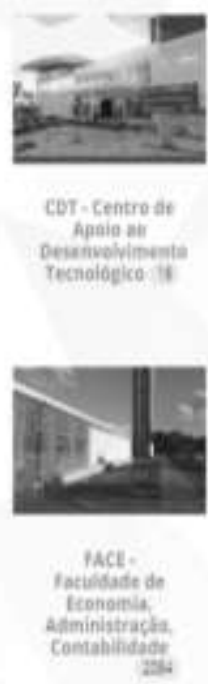

Fonte: Repositório Institucional UnB (2019)
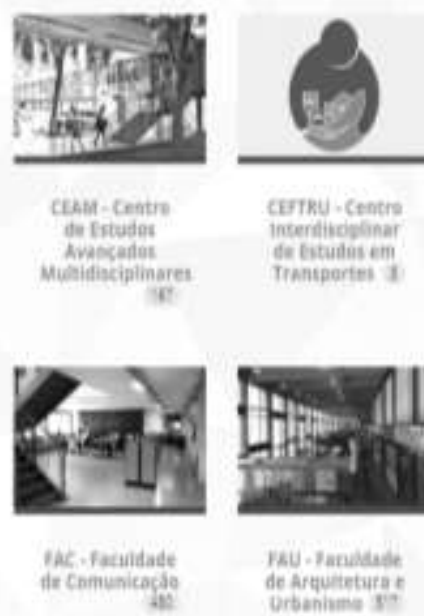

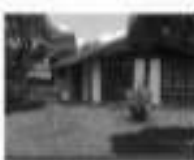

ca) - Cratre de Tiriami to

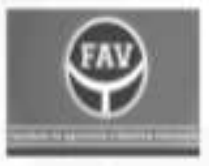

Iuv. faculiatity

andedicino

meterinering iey 
Figura 2 - Comunidades repositório institucional UFPE

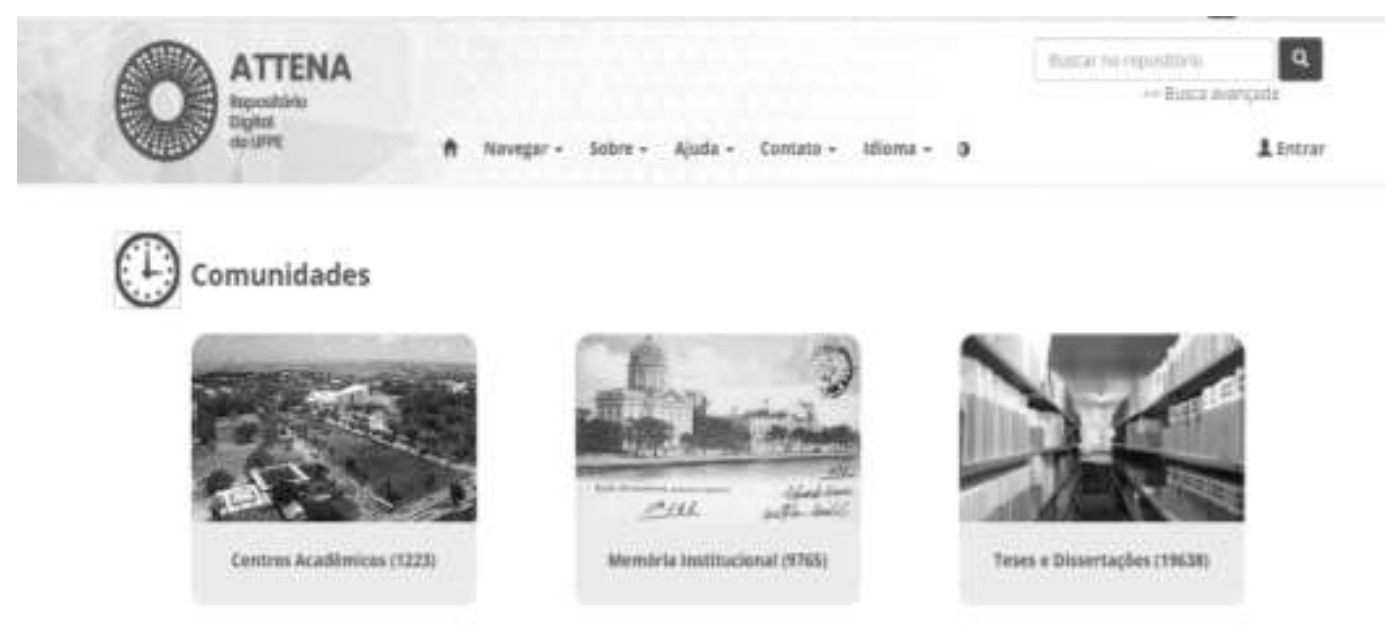

Fonte: Repositório Institucional UFPE (2019)

A UnB e a UFPE utilizam de imagens para dividir as comunidades de seus repositórios. Tal estratégia apresenta um ambiente bem segmentado e com ótima navegabilidade. Ao dispor de imagens, o repositório ficou organizado, sem ficar poluído, além de ser intuitivo ao usuário que procura a informação em determinada comunidade.

\subsection{Equipe}

A informação sobre equipe é interessante, pois pode servir de base para instituições que ainda não possuem repositórios na composição de seus recursos humanos em caso de uma possível implantação de um repositório em sua instituição. Leite (2009) menciona que a composição da equipe se torna mais rica quando for bastante multidisciplinar. Sobral e Santos (2017) acrescentam que essa equipe deve ser formada por Bibliotecários e profissionais capacitados em programação e tecnologia, pois os mesmos são capazes de criar mecanismos acessíveis de fácil manuseio aos usuários, realizar o povoamento do mesmo com documentos em diferentes formatos, além de prover o estabelecimento de interoperabilidade com outros repositórios. Pode-se afirmar que a equipe, com profissionais de diversas profissões e competências, oferece melhor custo benefício ao que é oferecido aos usuários.

A informação sobre equipe mostrou-se presente em nove instituições: UnB, Universidade Federal do Rio Grande (FURG), Universidade Federal da Bahia (UFBA), Universidade Tecnológica Federal do Paraná (UTFPR), Universidade Federal de Pernambuco (UFPE), Universidade Federal do Rio Grande do Norte (UFRN), Universidade Federal de Uberlândia (UFU), Universidade Federal de Ouro Preto (UFOP) e Universidade Federal Rural do Semi-Árido (UFERSA).

No repositório da UnB, a equipe responsável, disposta no seu site, é composta de três Bibliotecárias que dividem o trabalho entre os horários matutino e vespertino. $O$ repositório da FURG apresenta um comitê gestor que inclui diferentes Pró-reitorias, além de duas Bibliotecárias e nove Bolsistas. No repositório da UFBA, na página do serviço de alerta do

Perspectivas em Gestão \& Conhecimento, João Pessoa, v. 9, n. 2, p. 245-265, maio/ago. 2019. 
repositório, é possível verificar que há quatro pessoas responsáveis pela equipe editorial do mesmo. Um é ligado à editora da Universidade, outro, ao Instituto de Ciência da Informação e duas Estagiárias ligadas à editora da Universidade. O repositório também possui uma equipe técnica de cinco pessoas que assinam os manuais e tutoriais sobre o uso do mesmo. Na UTFPR, a responsável pela coordenação do mesmo é uma Bibliotecária e a informação que consta no repositório diz que a equipe toda é formada por Bibliotecários da instituição. Essa informação está disponível na aba "Sobre Riut", na subaba "Fale com o Comitê Gestor". Na UFPE, que atualizou o seu repositório em 2019, a informação sobre a equipe está na aba "Sobre", na subaba "Equipe técnica". É possível constatar que cabe a coordenação do repositório a uma Bibliotecária, sendo a sua equipe formada por Analista de Tecnologia da Informação e Bolsistas. O repositório da UFRN consta com Bibliotecárias e profissionais de Tecnologia da Informação. Esse repositório, diferente dos demais, apresenta uma fotografia dos componentes da equipe. A informação sobre a equipe no repositório da UFU está na aba "Sobre". Cabe a coordenação a uma Bibliotecária e a equipe é composta por Bibliotecários, Assistentes em Administração, Estagiário, Terceirizados e um Analista em Tecnologia da Informação.

A informação sobre a equipe nos repositórios analisados vai de encontro ao que Leite (2009) defende como sendo uma equipe com múltiplos conhecimentos. Interessante que, na maioria dos casos, a coordenação do repositório coube a um Bibliotecário. Segundo Belinato et al. (2017), a este profissional cabe a adaptação às mudanças constantes das ferramentas informacionais, uma vez que o mesmo utiliza a tecnologia como aliada ao seu trabalho. Portanto, o Bibliotecário é um elemento-chave na criação e implementação de repositórios institucionais, assim como na ampliação do Movimento de Acesso Aberto à informação científica (VIEIRA; SILVA, 2012).

A UFERSA apresenta em seu repositório a informação da equipe, que é composta por um Bibliotecário e um Analista de Tecnologia da Informação, mas não há a designação nominal de quais profissionais fazem este papel. Já na UFOP, a informação sobre a equipe foi encontrada via Google na página do sistema de bibliotecas da instituição. A coordenação do repositório está com uma Bibliotecária e a sua equipe é composta por dois Auxiliares em Administração e uma Auxiliar de Biblioteca.

\subsection{Manual}

Um manual, em aspecto amplo, estabelece os procedimentos e parâmetros de funcionamento de um repositório. Nele, está descrita as inter-relações possíveis no repositório de $\mathrm{A}$ a $\mathrm{Z}$. Em linhas gerais, o manual estabelece informações completas, bem elaboradas e exaustivas sobre um determinado objeto (neste caso, os repositórios institucionais das universidades federais brasileiras). Abaixo, o que foi encontrado em cada repositório analisado.

A informação sobre manual foi encontrada nos repositórios da UFBA, Universidade Federal de Sergipe (UFS), Universidade Federal de São Carlos (UFSCar), Universidade Federal do Rio de Janeiro (UFRJ), Universidade Federal do Vale do Jequitinhonha e Mucuri (UFVJM), Universidade Federal de Lavras (UFLA), Universidade Federal do Tocantins (UFT) e Universidade Federal de São Paulo (UNIFESP).

A UFBA dispõe de informações precisas em seu manual, como missão, objetivos e organização do repositório. Toda informação presente no manual também é segmentada e intuitiva, com linguagem clara e objetiva.

O manual do repositório da UFS está presente na aba "ajuda" do repositório e apresenta como o repositório está estruturado e como é possível fazer buscas no mesmo.

Perspectivas em Gestão \& Conhecimento, João Pessoa, v. 9, n. 2, p. 245-265, maio/ago. 2019. 
O repositório da UFSCar apresenta um manual que explica o que é o repositório e como é feito o autodepósito pelo autor.

A UFRJ também apresenta informações precisas como a missão, objetivos e organização do repositório, além de dispor de informações das tipologias documentais que estão inseridas no escopo do repositório, direitos autorais, criação de comunidades, subcomunidades e coleções, políticas de submissão e de preservação do repositório.

A UFVJM tem um manual bem limpo e explicativo, que contém a apresentação do repositório, informações sobre direitos autorais e cadastro dos usuários, autodepósito de documentos etc.

A UFLA apresenta um manual de orientação de uso do repositório em sua aba "políticas". Ele é bem elaborado, com linguagem de fácil compreensão, possui informações sobre como foi desenvolvido o repositório, organização das comunidades, políticas de conteúdo, gerenciamento, direitos autorais, acesso à informação e preservação; assim como o passo a passo para a submissão de trabalhos. Sua última atualização é de junho de 2018.

A UFT apresenta um documento de apresentação do repositório com orientações gerais do que é e como deve ser utilizado o repositório.

A UNIFESP apresenta um manual em HTML que foi encontrado via Google. O manual é bastante completo, utiliza do recurso de links para exemplificar o que é o repositório, o propósito do manual, como se faz uma pesquisa no repositório, como se registrar no sistema, como se inicia um depósito, como são compostas a comunidade e as coleções do repositório, formato de arquivos aceitos e como o usuário pode se cadastrar para receber informação atualizada do que é disponibilizado no repositório.

\subsection{Tutorial}

Um tutorial possui informação mais sucinta, prática e direta de ações a serem desempenhadas para o funcionamento do repositório. Nesta análise, foi possível verificar diferentes tutoriais em texto, com imagens e em vídeo. A seguir, uma explicação do que foi encontrado em cada repositório.

A Universidade Federal de Santa Catarina (UFSC) possui uma página a parte com informações sobre tutoriais, cujo link está presente no repositório. O repositório possui tutorial tanto em texto quanto em vídeo para diversas funcionalidades que o mesmo suporta. Todas as informações são segmentadas e há um tutorial para inserção de documentos no repositório, criação de coleções etc.

O repositório da Universidade Federal do Pampa (UNIPAMPA), na aba "documentos úteis", possui um tutorial de submissão bem simples e intuitivo de depósito no repositório. $O$ documento é de outubro de 2017. Ainda existe um tutorial da política de metadados do repositório. Isto denota que a instituição está preocupada com o controle de autoridades do sistema. O controle de autoridades em repositórios é uma tendência que tem despertado o interesse das instituições. Quando bem delineado, há a padronização dos metadados, o que auxilia positivamente na recuperação da informação no sistema.

No repositório da FURG, o documento para o tutorial de submissão no sistema está na aba "documentos". No mesmo, há uma explicação breve do que é um repositório institucional e o passo a passo de como fazer a submissão de trabalhos no mesmo.

A UFTPR apresenta um tutorial, em vídeo, que explica os repositórios da instituição, dentre eles, o institucional. O vídeo foi encontrado via Google, no site de tutoriais da biblioteca da instituição. $O$ vídeo atualiza os usuários do propósito de cada repositório, a definição e o alinhamento com as práticas de acesso aberto pela instituição. O sistema de bibliotecas também é explicado no vídeo.

Perspectivas em Gestão \& Conhecimento, João Pessoa, v. 9, n. 2, p. 245-265, maio/ago. 2019. 
$\mathrm{Na}$ Universidade Federal da Integração Latino-Americana (UNILA), o tutorial não estava aparente no repositório, mas sim no Google. A estratégia adotada para encontrar o documento no buscador foi: "UNILA" + "Tutorial" + "Repositório". O documento também apresenta o passo a passo para a submissão de documentos no repositório, que é assinado por um Bibliotecário.

O repositório da Universidade Federal do Rio Grande do Sul (UFRGS) apresenta tutoriais dentro do repositório na aba "Ajuda". Lá é possível verificar como se faz uma busca no repositório, pesquisar por listas, compartilhamento em mídias sociais, a utilização de termos e estratégias de buscas, como o uso de operadores booleanos, o que é e o que serve um handle (identificador persistente que garante a segurança e integralidade do link, mesmo em caso de migração de sistemas) dentro de um repositório. Ao buscar pelo Google, também foi possível encontrar outro tutorial do repositório bastante completo dentro do site de documentação dos serviços de TI da instituição.

A Universidade Federal do Paraná (UFPR) possui tutoriais em vídeos que são acessados através de busca no repositório.

$\mathrm{Na}$ aba "como depositar" do repositório da UFBA, há um tutorial que ensina o depósito informacional. O tutorial é de 2010 e assinado pelos renomados Milton Shintaku e Rodrigo França Meirelles.

A Universidade Federal de Alagoas (UFAL) apresenta um tutorial de vídeo que foi encontrado via Google. O tutorial, de forma básica, apresenta o repositório e como se faz pesquisas no mesmo.

A UFPE atualizou o seu repositório recentemente. No site da instituição, na parte de notícias, há um vídeo, em forma de entrevista, que apresenta a nova interface do repositório e como se faz pesquisas no mesmo. É uma explicação simples, mas que pode ser útil ao público leigo.

Na Universidade Federal do Ceará (UFC), os tutoriais foram encontrados via Google. A informação está dentro do site da biblioteca da instituição. Frente a esses casos, em que se encontrou esses documentos pelo Google, salienta-se que o ideal seria que os mesmos estivessem dentro do repositório.

$\mathrm{Na}$ aba "sobre" do repositório institucional da UFRN, há um tutorial em Word de preenchimento de metadados do repositório. É um tutorial que explica o método pelo qual se deve entrar a autoria para evitar erros e duplicatas; a elaboração de referências frente às diferentes tipologias documentais que comportam o repositório etc.

A Universidade Federal do Amazonas (UFAM) apresenta dois tutoriais na aba "documentos" de seu repositório. Os tutoriais em questão são o de uso e o de liberação de relatórios. O tutorial de uso apresenta como se navega no repositório, como se faz uma pesquisa, como se cadastrar e como se faz depósitos; o de liberação de relatórios diz respeito aos relatórios de iniciação científica da instituição. São tutoriais muito completos e explicativos.

A Universidade Federal de Ouro Preto (UFOP), na aba "documentos", apresenta um tutorial para a submissão de documentos no repositório que é bem sucinto e direto.

A UFSCar apresenta um tutorial em vídeo do fluxo de autoarquivamento de teses e dissertações no repositório, além de dispor de um infográfico de fluxo de autoarquivamento do mesmo.

A UFU possui uma aba no repositório chamada "tutoriais", que dá acesso aos documentos com explicações de como é feito o autoarquivamento de teses e dissertações; deliberações sobre a importância do PDF/A (formato de arquivo eletrônico de autoarquivamento em longo prazo); autoarquivamento de Trabalhos de Conclusão de Curso e cadastro de usuários.

Perspectivas em Gestão \& Conhecimento, João Pessoa, v. 9, n. 2, p. 245-265, maio/ago. 2019. 
A Universidade Federal Fluminense (UFF), na aba "documents" do repositório, traz um tutorial para a criação de comunidades e/ou coleções no mesmo. Esse tutorial não é muito preciso, apenas apresenta deliberações que devem ser encaminhadas ao setor responsável para a criação de comunidades, coleções e permissões no repositório. Também há um pequeno passo a passo de cadastro de usuário.

A Universidade Federal do Pará (UFPA) oferece um documento que orienta para a submissão de documentos no repositório, o conteúdo que é aceito no escopo do repositório, diretrizes de acesso e uso do mesmo. Ainda há um documento da política de metadados adotada pela instituição.

Em suma, o manual e o tutorial servem de guia ao usuário e ao público leigo que está tendo contato com o sistema. Portanto, instituições se debruçam no desenvolvimento desses documentos detalhando as funcionalidades do repositório. Alguns desses documentos não foram encontrados dentro do repositório, conforme sinalizou a pesquisa. E isso é uma questão que deveria ser pensada e considerada pela equipe que coordena os repositórios.

\subsection{Política}

Sobre políticas, Marcondes e Sayão (2009, p. 18) informam que podem variar

[...] desde a simples sugestão de que os pesquisadores depositem cópias de livre acesso de seus trabalhos aceitos em periódicos ou congressos, passando por diferentes tipos de incentivos para que seja feito o autoarquivamento até a obrigatoriedade institucional de o fazerem.

Já Camargo e Vidotti (2009, p. 65) justificam as políticas em um ambiente científico digital como um processo de orientação das coleções e garantem visibilidade do repositório, prevendo

[...] forma de acesso, tipo de documentos, restrições ao nível do conteúdo do documento, formas de depósito de documentos, tipologias de formatos, formato de documentos, digitalização de documentos, normalização de formatos, segurança e preservação da informação e normalização para documentos eletrônicos. Cada política varia de acordo com o tipo de ambiente e deve ser adequada ao contexto do objeto informacional. É importante ressaltar que os ambientes informacionais precisam adotar políticas e diretrizes de auto-avaliação e auto-reajuste/realimentação, bem como ter transparência na divulgação de resultados e utilizar critérios de reconhecimento pessoal para impulsionar a motivação para o sucesso do ambiente informacional.

Portanto, quando a política de um repositório é definida, é possível estabelecer e padronizar ações realizadas dentro do mesmo. Leite (2009) elenca outras políticas que podem compor um repositório como: políticas de desenvolvimento de coleções, políticas de direitos autorais, política de preservação digital, política de informação, políticas de gestão da informação em ambiente digital, entre outras. Todas funcionam em conjunto, padroniza e fortalece as ações que forem tomadas dentro do repositório.

Das 49 universidades com repositórios e com acesso disponível, verificou-se que 35 possuem política. A política, como demonstrado, é um documento essencial que apresenta o propósito de existência do mesmo. Desses, listou-se algumas instituições cujas políticas foram encontradas pelo Google e, consequentemente, fora do repositório: Universidade Federal de

Perspectivas em Gestão \& Conhecimento, João Pessoa, v. 9, n. 2, p. 245-265, maio/ago. 2019. 
Ciências da Saúde de Porto Alegre (UFCSPA), Universidade Federal da Grande Dourados (UFGD), Universidade de Goiás (UFG), Universidade Federal de Itajubá (UNIFEI), Universidade Federal de Mato Grosso do Sul (UFMS) e Universidade Federal de Viçosa (UFV). O documento da UFCSPA está no site de documentos institucionais da universidade. A UFGD, UFMS e a UNIFEI na página da instituição sobre a biblioteca. A UFG, dentro da página de normativas da instituição. A UFV dispõe do documento no site de secretaria de órgãos colegiados.

\subsection{Mensagens eletrônicas e ouvidorias}

Para a UFAC, que estava com acesso indisponível durante a pesquisa, foi enviada mensagem eletrônica, no entanto, não houve retorno de seus responsáveis. Mediante a este contexto, procurou-se a ouvidoria da instituição, com o respaldo da Lei de Acesso à Informação, mas também sem retorno.

O contato com a Universidade Federal de Campina Grande (UFCG), Universidade Federal do Cariri (UFCA), Universidade Federal do Oeste da Bahia (UFOB), Universidade Federal de São João del-Rei (UFSJ) e Universidade Federal do Triângulo Mineiro (UFTM), instituições que não possuíam repositórios durante a análise dessa pesquisa, também se deu por e-mail, em primeiro momento, e, posteriormente, caso as instituições não retornassem o contato, procurou-se as ouvidorias, mas nenhuma delas retornou o contato.

A Universidade Federal do Oeste do Pará (UFOPA) informou que a universidade desenvolve um projeto de repositório institucional, porém, ainda em fase inicial.

A Universidade Federal de Alfenas (UNIFAL-MG) não criou o seu repositório e não deu expectativas de quando será criado.

A Universidade Federal do $A B C$ (UFABC) informou que trabalha para colocar o repositório no ar no primeiro semestre de 2018. No entanto, até a presente data, julho de 2019, o repositório ainda não está no ar.

A Universidade Federal Rural do Rio de Janeiro (UFRRJ) possui um repositório do Instituto Multidisciplinar, que fica localizado na cidade de Nova Iguaçu, região metropolitana do Rio de Janeiro. Segundo mensagem recebida, a ideia é de o repositório atender, futuramente, a universidade como um todo.

A Universidade Federal do Sul da Bahia (UFSB) estuda a viabilidade de disponibilizar, no futuro, um acervo eletrônico, mas espera com o tempo aumentar a sua produção científica, o que justifica a implantação de um repositório. Este aumento é proveniente da produção de programas de pós-graduação. Atualmente, a produção é disponibilizada no Pergamum (catálogo online) da instituição, cujos materiais recebem um link para acesso completo em formato PDF.

A Universidade Federal do Vale do São Francisco (UNIVASF) informou que o repositório está em fase de implantação. A política do mesmo está como pauta do Conselho Universitário para ser apresentado e votado.

A Universidade Federal do Amapá (UNIFAP) informou que, em 2015, foi criada uma comissão para a implantação de um repositório institucional, mas as discussões não avançaram.

A Universidade Federal de Minas Gerais (UFMG) está em fase de testes do seu repositório. A instituição espera que o repositório institucional possa unir os demais repositórios da instituição, com a finalidade de centralizar tudo em um mesmo sítio na internet. Os treinamentos dos Bibliotecários já foram iniciados. O projeto conta com a coordenação de uma Bibliotecária e o apoio do setor de Tecnologia da Informação da instituição.

Perspectivas em Gestão \& Conhecimento, João Pessoa, v. 9, n. 2, p. 245-265, maio/ago. 2019. 


\section{CONSIDERAÇÕES FINAIS}

A pergunta que norteou a presente pesquisa foi: como está delineado o panorama dos repositórios institucionais das universidades federais brasileiras, no que diz respeito à adoção de software, equipe, confecção e elaboração de manuais e/ou tutoriais e políticas? Acredita-se que a pesquisa conseguiu desmembrar a pergunta em questão. O repositório que cumpriu todos os quesitos foi o da UFBA. O repositório da UFBA possui uma interface limpa e intuitiva. Existem links para saber o que é o repositório institucional da universidade, orientações de uso, tutorial de como realizar um depósito no mesmo e mecanismo para a criação de alerta, ou seja, diretamente ligado à Disseminação Seletiva da Informação (DSI). Em segundo lugar, aparecem UFSCar, FURG, UTFPR, UFPE, UFRN, UFOP e UFU. Os quesitos de maior pontuação entre essas instituições foram política e tutorial, ambos com (7), equipe com (6) e manual com (1). Cabe lembrar que a informação sobre equipe da UFOP não foi encontrada dentro do repositório, mas, na consideração da situação hipotética de construção de um, a informação disponibilizada por eles seria válida. Já na UFTPR, o tutorial também foi encontrado fora do repositório. É um tutorial que poderia enriquecer o repositório caso colocado dentro do mesmo.

De forma ampla, a informação sobre o manual apresentou-se em menor número nos quesitos pesquisados (8), seguido de equipe (9), tutorial (18) e política (35). Acredita-se que manuais e tutoriais se apresentam como documentos elementares e norteadores para 0 público leigo. A existência desses documentos ajuda a suprir qualquer dificuldade inicial que possa vir a surgir ao usuário que acessa o repositório. Cabe lembrar que a composição dos estudantes das universidades federais foi modificada com a implantação da expansão do ensino. Portanto, com um público heterogêneo, cresceu as preocupações com a criação e compilação de produtos de informação mais robustos.

Sobre a equipe, notou-se que a profissão que aparece com maior incidência é a de bibliotecário, ou seja, o dito profissional da informação foi a profissão que apareceu com maior frequência na coordenação e no gerenciamento dos repositórios. Profissionais de Sistemas e Tecnologia da Informação também aparecem e são importantes junto com o bibliotecário no bom funcionamento do repositório.

O quesito que compreendeu maior adesão nos repositórios, neste caso sem computar o quesito software, foi o quesito política (35 instituições de 49), sendo um número considerável, pois apenas 14 não dispõem do documento ou o mesmo não estava disponível de forma aparente. Na pesquisa, verificou-se que alguns estavam disponíveis em outros sites de setores e departamentos da instituição, e não no repositório. Esta prática poderia ser revista pelos coordenadores dos repositórios, uma vez que é interessante a presença do documento dentro do repositório, pois evita pesquisa paralela pelo usuário, sem tomar tempo da pesquisa principal. A política delimita os propósitos em se construir um repositório, ou seja, demonstra que é necessário ter um planejamento definido, cujas etapas devem ser seguidas para a fundamentação da sua existência. Com a definição da política institucional, ficam explícitos elementos norteadores para passos futuros, podendo isto ser considerada como um instrumento de advocacy.

Por regiões geográficas, verificou-se que o Sul e o Centro-oeste são as únicas em que todas as universidades federais que apresentavam repositórios em funcionamento, sem nenhuma interrupção. Os repositórios da UFSM e o da UFRGS não se apresentam como "institucional", mas sim como "digital". Ainda assim, na descrição dos repositórios, em seus respectivos sites, ficou claro que os mesmos são institucionais. Caso que não ficou claro na Biblioteca de Teses e Dissertações (BDTD) da UFCG. A UFSM e UFRGS apresentam que o repositório tem como objetivo reunir, preservar e divulgar a produção de todo o corpus da universidade.

Perspectivas em Gestão \& Conhecimento, João Pessoa, v. 9, n. 2, p. 245-265, maio/ago. 2019. 
A pesquisa também alerta para a dificuldade de conseguir informação em algumas universidades, mesmo amparada pela Lei de Acesso à Informação. Algumas universidades não retornaram as mensagens dos autores.

Percebeu-se, em alguns repositórios, a presença de plug-ins de compartilhamento que remetem às mídias sociais como YouTube, Facebook e Twitter. O YouTube, por sinal, tem sido utilizado por algumas instituições como canal de divulgação dos tutoriais do repositório. Damasceno (2015) justifica que são por meio das mídias sociais que $72 \%$ da população de países emergentes buscam informação. Esta informação poderá servir de base para estudos futuros sobre impactos que as mídias sociais representam para os repositórios institucionais.

Ao realizar a pesquisa de 2017 a 2019, foi possível constatar algumas questões: a) no primeiro período da pesquisa (2017-2018), eram 46 universidades com repositórios, sem contar a UFAC, que ainda continuava com acesso indisponível, e a UFRA, que também estava com o acesso indisponível; b) neste período, a UNIRIO não possuía o repositório no ar, mas já caminhava para a implantação do mesmo conforme resposta a esta pesquisa pela Bibliotecária do setor de informação digital da instituição na época; c) apenas UnB, FURG e UFBA possuíam informação sobre a composição da equipe do repositório; d) a política da UNILA era encontrada via Google e hoje já está dentro do repositório; e) o Governo Federal, na época com Michel Temer como Chefe de Estado, havia autorizado a criação de 5 universidades federais, no entanto, essa decisão foi revista, retomando as 63 universidades iniciais.

Neste contexto, concluiu-se que a política é o critério de maior adesão nos repositórios analisados, ainda que esta pesquisa apresente algumas limitações como, por exemplo, as constantes atualizações dos repositórios, ou seja, com o avanço tecnológico, o quadro aqui apresentado pode se tornar defasado. Outro ponto considerado está nas dispersões de documentos importantes sendo alocado em sites, que não seja o próprio repositório, algo que não poupa o tempo do usuário, como orienta uma das cinco leis da Biblioteconomia.

\section{REFERÊNCIAS}

ANDRADE, V. T. A. de. Uma plataforma de ciência aberta para o Brasil. In: CONGRESSO LATINOAMERICANO DE INVESTIGADORES DE LA COMUNICACIÓN, 12., 2014, Lima. Anais eletrônicos... Lima: ALAIC, 2014. Disponível em: http://congreso.pucp.edu.pe/alaic2014/wpcontent/uploads/2013/12/GI1-Viviane-ToraciAlonso-de-Andrade.pdf. Acesso em: 12 jul. 2019.

BELENS, A. J.; PORTO, C. M. Ciência e tecnologia, uma abordagem na sociedade da informação. In: PORTO, C. M. (org). Difusão e cultura científica: alguns recortes. Salvador: EDUFBA, 2009. p. 45-73.

BELINATO, B. B. et al. A formação continuada do bibliotecário: um prisma multidisciplinar. Revista Brasileira de Biblioteconomia e Documentação, São Paulo, v. 13, n. esp. CBBD 2017, p. 2538-2550, 2017. Disponível em: https://rbbd.febab.org.br/rbbd/article/view/1000/954. Acesso em: 12 jul. 2019.

BRASIL. Lei 12.527, de 18 de novembro de 2011. Regula o acesso a informações previsto no inciso XXXIII do artigo 5o, no inciso II do \& 30 do art. 37 e no \& 20 do art.216 da Constituição Federal; altera a Lei n.8.112, de 11 de dezembro de 1990; revoga a lei n.11.111, de 5 de maio de 2005, e dispositivos da Lei n. 8.159, de 8 de janeiro de 1991; e dá outras providências. Diário Oficial [da] União. Brasília, DF: 18 nov. 2011. Disponível em: 
http://www.planalto.gov.br/ccivil 03/ ato2011-2014/2011/lei/l12527.htm. Acesso em: 10 mar. 2018.

BRASIL. Ministério da Educação. Coordenação de Aperfeiçoamento de Pessoal de Nível Superior. Portaria no 13, de 15 de fevereiro de 2006. Brasília, DF: CAPES, 15 fev. 2006. Disponível em: http://repositorio.unb.br/documentos/Portaria N13 CAPES.pdf. Acesso em: 14 jul. 2019.

BRASIL. Ministério da Educação. e-MEC. 2019. Disponível em: http://emec.mec.gov.br/. Acesso em: 26 jan. 2018.

BUDAPEST OPEN ACCESS INITIATIVE (BOAI). Declaração de Budapeste. 2002. Disponível em: http://www.budapestopenaccessinitiative.org/. Acesso em: 12 jul. 2019.

CAMARGO, L. S. de A. de; VIDOTTI, S. A. B. G. Arquitetura da informação para repositórios digitais. In: SAYÃO, L. F. et al. (org.). Implantação e gestão de repositórios institucionais: políticas, memória, livre acesso e preservação. Salvador: EDUFBA, 2009. p. 55-82. Disponível em: https://repositorio.ufba.br/ri/bitstream/ufba/473/3/implantacao repositorio web.pdf.

CIVALLERO, E. Open access: experiencias latino-americanas. In: CONGRESO INTERNACIONAL DE BIBLIOTECOLOGÍA E INFORMACIÓN, 2., 2006, Lima. Anales electrónicos... Lima: Colégio de Bibliotecólogos del Peru., 2006.2 Disponível em: https://www.aacademica.org/edgardo.civallero/80.pdf. Acesso em: 13 jun. 2019.

CLARIVATE Analytics. Research in Brazil: a report for CAPES by Clarivate Analytics. [Philadelphia: Clarivate Analytics], 2017. 73 p. Disponível em: http://www.capes.gov.br/images/stories/download/diversos/17012018-CAPES-InCitesReportFinal.pdf. Acesso em: 15 fev. 2018.

DAMASCENO, S. Mídias sociais são a 1ạ fonte de informação. Meio\&mensagem, São Paulo, 30 jan. $2015 . \quad$ Disponível em: http://www.meioemensagem.com.br/home/midia/2015/01/30/midias-sociais-sao-primeirafonte-de-informacaoo.html. Acesso em: $27 \mathrm{dez} .2017$.

DSPACE. About DSPACE. Disponível em: http://www.dspace.org/introducing. Acesso em: 29 dez. 2017.

FICHE, R. H.; MOURA, L. R. C.; MAIA, L. C. G. A utilização dos repositórios digitais encontrados nas organizações. RACln, João Pessoa, v. 5, n. 1, p. 61-80, 2017. Disponível em: http://www.luizmaia.com.br/docs/2017-racin v5 n1 artigo04.pdf. Acesso em: 15 jul. 2019.

FOLHA DE SÃO PAULO. 2018. Ranking de universidades. Disponível em: http://ruf.folha.uol.com.br/2018/ranking-de-universidades/. Acesso em: 29 jan. 2018.

FOSTER. Open science definition. 2018. Disponível em: https://www.fosteropenscience.eu/taxonomy/term/100. Acesso em: 28 dez. 2018.

FURNIVAL, A. C.; HUBBARD, B. Acesso aberto às publicações científicas: vantagens, políticas e advocacy. InCID, Ribeirão Preto, v. 2, n. 2, p. 160-177, 2011.

Perspectivas em Gestão \& Conhecimento, João Pessoa, v. 9, n. 2, p. 245-265, maio/ago. 2019. 
GIL, A. C. Como elaborar projetos de pesquisa. 4. ed. São Paulo: Atlas, 2007.

GUANAES, P. C. V.; GUIMARÃES, M. C. S. Acesso aberto: uma nova crise no horizonte?. Comciência, Campinas, n. 39, 2012. Disponível em: http://www.cs.cornell.edu/ ginsparg/physics/blurb/pg01unesco.html. Acesso em: 10 jul. 2019.

GUIMARÃES, M. C. S.; SILVA, C. H.; NORONHA, I. H. Los repositórios temáticos en la estratégia de la iniciativa Open Access. Nutrición Hospistalaria, Madrid, v. 27, Supl. 2, p. 34-40, 2012. Disponível em: http://scielo.isciii.es/pdf/nh/v27s2/05articulo05.pdf. Acesso em: 15 jul. 2019.

HANARD, S. et al. The green and the gold roads to open access. Nature Web Focus, London, 2004. Disponível em: http://www.nature.com/nature/focus/accessdebate/21.html. Acesso em: 27 dez. 2017.

IBICT. Sobre o DSPACE. 2017. Disponível em: http://www.ibict.br/pesquisa-desenvolvimentotecnologico-e-inovacao/Sistema-para-Construcao-de-Repositorios-Institucionais-Digitais.

Acesso em: 28 dez. 2017.

INSTITUTO BRASILEIRO DE INFORMAÇÃO EM CIÊNCIA E TECNOLOGIA. Edital de chamada FINEP/PCAL/XBDB no. 002/2009. Brasília, DF: IBICT, 2009.

KORNALEWSKI, A. M.; BORGES, L. da C.; BELINATO, B. B. Repositório biográfico: singularidades de um modelo promissor. Revista Eletrônica de Comunicação, Informação \& Inovação em Saúde, Rio de Janeiro, v. 11, 2017. Disponível em: https://www.reciis.icict.fiocruz.br/index.php/reciis/article/view/1415/pdf1415. Acesso em: 14 jul. 2019.

KURAMOTO, H. AO: mitos e verdades III. Blog do Kuramoto, [S.I.], ago. 2011. Disponível em: https://kuramoto.wordpress.com/2011/08/13/oa-mitos-e-verdades-iii/. Acesso em: 14 abr. 2018.

KURAMOTO, H. Estatísticas sobre repositórios no Brasil. Blog do Kuramoto, [S.I.], out. 2012. Disponível em: https://kuramoto.wordpress.com/2012/10/30/estatisticas-sobre-ri-no-brasil/. Acesso em: 29 dez. 2017.

KURAMOTO, H. Informação científica: proposta de um novo modelo para o Brasil. Ciência da Informação, Brasília, DF, v.35, n. 2, p. 91-102, maio/ago. 2006. Disponível em: http://www.scielo.br/scielo.php?pid=S010019652006000200010\&script=sci abstract\&tIng=pt. Acesso em: 29 dez. 2017.

LEITE, F. C. L. Como gerenciar e ampliar a visibilidade da informação científica brasileira: repositórios institucionais de acesso aberto. Brasília, DF: IBICT, 2009. Disponível em: http://livroaberto.ibict.br/bitstream/1/775/4/Como\%20gerenciar\%20e\%20ampliar\%20a\%20vi sibilidade\%20da\%20informa\%C3\%A7\%C3\%A30\%20cient\%C3\%ADfica\%20brasileira.pdf. Acesso em: 26 dez. 2017.

MARCONDES, C. H.; SAYÃO, L. F. À guisa de introdução: repositórios institucionais e livre acesso. In: SAYÃO, L. F. et al. (org.). Implantação e gestão de repositórios institucionais: políticas, memória, livre acesso e preservação. Salvador: UFBA, 2009. p. 9-21. Disponível em:

Perspectivas em Gestão \& Conhecimento, João Pessoa, v. 9, n. 2, p. 245-265, maio/ago. 2019. 
https://repositorio.ufba.br/ri/bitstream/ufba/473/3/implantacao repositorio web.pdf. Acesso em: 10 dez. 2017.

MÁRDERO ARELLANO, M. Á. Critérios para a preservação digital da informação científica. 2008. Tese (Doutorado em Ciência da Informação) - Faculdade de Ciência da Informação, Universidade de Brasília, Brasília, DF. Disponível em: https://core.ac.uk/download/pdf/11884842.pdf. Acesso em: 10 jul. 2019.

MARTINS, C. F. Como escolher o repositório institucional adequado à sua IES. ABMES, Brasília, DF, 2019. Disponível em: https://blog.abmes.org.br/como-escolher-o-repositorio-institucionaladequado-a-sua-ies/. Acesso em: 27 jul. 2019.

MELIS, M. F. M. Os critérios para cadastramento no opendoar e os repositórios institucionais luso-brasileiros. INCID: Revista de Ciência da Informação e Documentação, Ribeirão Preto, v. 4, n. 2, p. 20-33, jul./dez. 2013. Disponível em: http://www.revistas.usp.br/incid/article/view/69268. Acesso em: 02 jan. 2018.

MONTEIRO, F.; BRÄSCHER, M. Organização da informação em repositórios temáticos: o uso da modelagem conceitual. In: ENCONTRO NACIONAL DE PESQUISA EM CIÊNCIA DA INFORMAÇÃO; 8., 2007, Salvador. Anais eletrônicos... Salvador: ENANCIB; 2007. Disponível em: http://www.enancib.ppgci.ufba.br/artigos/GT2--261.pdf. Acesso em: 15 jul. 2019. p. 1-12.

MUELLER, S. P. M. A comunicação científica e o movimento de acesso livre ao conhecimento. Ciência da Informação, Brasília, DF, v. 35. n. 2, p. 27-38, 2006. Disponível em: http://revista.ibict.br/ciinf/article/view/1138. Acesso em: 10 dez. 2017.

OPENDOAR. Open access repositor types: worldwide. 2018. Disponível em: http://v2.sherpa.ac.uk/opendoar/. Acesso em: 20 jul. 2019.

PIMENTA, D. N. et al. Repositórios temáticos e memória: a constituição da educação em saúde no Brasil por meio da trajetória de Virgínia Schall. Cadernos BAD, Lisboa, n. 2, p. 145-152, $2016 . \quad$ Disponível em: https://www.bad.pt/publicacoes/index.php/cadernos/article/view/1593/pdf. Acesso em: 10 jul. 2019.

PINHEIRO, L. V. R. Do acesso livre à ciência aberta: conceitos e implicações na comunicação científica. Revista Eletrônica de Comunicação Informação \& Inovação em Saúde, Rio de Janeiro, v. $8, \quad$ n. 2, p. 153-165, 2014. Disponível em: https://www.reciis.icict.fiocruz.br/index.php/reciis/article/view/629/1269. Acesso em: 10 jul. 2019.

RODRIGUES, E. Acesso livre ao conhecimento: a mudança do sistema de comunicação da ciência e os profissionais de informação. Cadernos Bad, Lisboa, n.1, p. 24-35. 2004. Disponível em: http://www.bad.pt/publicacoes/index.php/cadernos/article/view/836/835. Acesso em: 10 dez. 2017.

ROMANI, L. S.; FUSCO, E.; SANTOS, P. L. V. A. C. Análise e implantação de repositório digital educacional utilizando software livre DSPACE. In: CONGRESSO INTERNACIONAL DE EDUCAÇÃO DE PONTA GROSSA, 2., Ponta Grossa, 2010. Anais eletrônicos... Ponta Grossa: UEPG, 2010. p.

Perspectivas em Gestão \& Conhecimento, João Pessoa, v. 9, n. 2, p. 245-265, maio/ago. 2019. 
1-14. Disponível em: http://www.lbd.dcc.ufmg.br/colecoes/sbsi/2010/0019.pdf. Acesso em: 19 jul. 2019.

SANTOS JUNIOR, E. R. dos. Repositórios institucionais de acesso livre no Brasil: estudo delfos. 2010. Dissertação (Mestrado em Ciência da Informação) - Faculdade de Ciência da Informação, Universidade de Brasília, Brasília, DF.

SIDONE, O. J. G.; HADDAD, E. A.; MENA-CHALCO, J. P. A ciência nas regiões brasileiras: evolução da produção e das redes de colaboração. Transinformação, Campinas, v. 28, n. 1, p. 15-31, jan./abr. 2016. Disponível em: http://www.scielo.br/pdf/tinf/v28n1/0103-3786-tinf-2801-00015.pdf. Acesso em: 15 dez. 2018.

SILVA, D. M. A. O desafio do profissional da informação na gestão de repositórios institucionais nacionais. In: ENCONTRO NACIONAL DE ENSINO E PESQUISA EM INFORMAÇÃO, 13., Salvador, 2017. Anais eletrônicos [...], Salvador: EDUFBA, 2017. p. 569-579. Disponível em: http://www.cinform2017.ufba.br/. Acesso em: 27 nov. 2017.

SOBRAL, R. M.; SANTOS, C. A. C. M. dos. Repositórios institucionais digitais de informação científica: implementação com o software DSPACE como solução técnica. PRISMA.COM, Porto, n. 35, p. 152-184, 2017. Disponível em: https://ojs.letras.up.pt/index.php/prismacom/article/view/3516/3308. Acesso em: 15 jul. 2019.

SUBER, P. A very brief introduction to open access. 2004. Disponível em: https://legacy.earlham.edu/ peters/fos/brief.htm. Acesso em: 10 fev. 2018.

TRISKA, R.; CAFÉ, L. Arquivos abertos: subprojeto da biblioteca digital brasileira. Ciência da Informação, Brasília, DF, v. 30, n. 3 p. 92-96, 2001. Disponível em: http://revista.ibict.br/ciinf/article/view/917/954. Acesso em: 20 jul. 2019.

VIEIRA, E. A.; SILVA, T. C. B. A. da. O papel do bibliotecário na implementação de repositórios institucionais. Biblionline, João Pessoa, v. 8, n. 1, p. 86-94, 2012. Disponível em: http://www.brapci.inf.br/index.php/res/download/51520. Acesso em: 10 jul. 2019. 